\title{
Role of Aldosterone and Mineralocorticoid Receptor in Cardiovascular Aging
}

\author{
Stefania Gorini ${ }^{1 \dagger}$, Seung Kyum Kim ${ }^{2,3+}$, Marco Infante ${ }^{4}$, Caterina Mammi ${ }^{1}$, \\ Sandro La Vignera ${ }^{5}$, Andrea Fabbri ${ }^{4}$, Iris Z. Jaffe ${ }^{2}$ and Massimiliano Caprio ${ }^{1,6 *}$ \\ ${ }^{1}$ Laboratory of Cardiovascular Endocrinology, IRCCS San Raffaele Pisana, Rome, Italy, ${ }^{2}$ Molecular Cardiology Research \\ Institute, Tufts Medical Center, Boston, MA, United States, ${ }^{3}$ Department of Sports Science, Seoul National University of \\ Science and Technology, Seoul, South Korea, ${ }^{4}$ Unit of Endocrinology and Metabolic Diseases, Department of Systems \\ Medicine, CTO A. Alesini Hospital, ASL Roma 2, University of Rome Tor Vergata, Rome, Italy, ${ }^{5}$ Department of Clinical and \\ Experimental Medicine, University of Catania, Catania, Italy, ${ }^{6}$ Department of Human Sciences and Promotion of the Quality of \\ Life, San Raffaele Roma Open University, Rome, Italy
}

The mineralocorticoid receptor (MR) was originally identified as a regulator of blood pressure, able to modulate renal sodium handling in response to its principal ligand aldosterone. MR is expressed in several extra-renal tissues, including the heart, vasculature, and adipose tissue. More recent studies have shown that extra-renal MR plays a relevant role in the control of cardiovascular and metabolic functions and has recently been implicated in the pathophysiology of aging. MR activation promotes vasoconstriction and acts as a potent pro-fibrotic agent in cardiovascular remodeling. Aging is associated with increased arterial stiffness and vascular tone, and modifications of arterial structure and function are responsible for these alterations. MR activation contributes to increase blood pressure with aging by regulating myogenic tone, vasoconstriction, and vascular oxidative stress. Importantly, aging represents an important contributor to the increased prevalence of cardiometabolic syndrome. In the elderly, dysregulation of MR signaling is associated with hypertension, obesity, and diabetes, representing an important cause of increased cardiovascular risk. Clinical use of MR antagonists is limited by the adverse effects induced by MR blockade in the kidney, raising the risk of hyperkalaemia in older patients with reduced renal function. Therefore, there is an unmet need for the enhanced understanding of the role of MR in aging and for development of novel specific MR antagonists in the context of cardiovascular rehabilitation in the elderly, in order to reduce relevant side effects.

Keywords: endothelial dysfunction, mineralocorticoid receptor, vascular stiffness, RAAS, oxidative stress

\section{INTRODUCTION}

The mineralocorticoid receptor (MR) is essential for blood pressure regulation and electrolyte and fluid homeostasis (1). MR activation by aldosterone evolved in response to dramatic changes in salt stress which occurred during the transition from aquatic to terrestrial life. Indeed, aldosterone first appeared in tetrapods (2) suggesting that the aldosterone-MR system was necessary to maintain ion balance during the transition from salt water to land. In mammals, the kidney maintains osmolarity and extracellular sodium concentration, as well as plasma volume and blood 
pressure (3). Aldosterone is produced by the adrenal glands and represents the most potent sodium-retaining hormone in mammals (4). Aldosterone secretion is stimulated under specific conditions, such as the increase in extracellular $\mathrm{K}^{+}$ion concentrations or renin-angiotensin-aldosterone system (RAAS) activation in response to decreased vascular volume $(5,6)$. In addition to its well-established role in the kidney, MR is expressed in many non-epithelial tissues [i.e., adipose tissue (AT), heart, endothelial cells, vascular smooth muscle cells, brain, etc.]. In this context, abnormal MR activation contributes to relevant cardiovascular alterations by multiple mechanisms including enhanced oxidative stress, inflammation, fibrosis, vascular tone, and endothelial dysfunction (7). Importantly, MR displays a similar affinity for aldosterone and the physiological glucocorticoids (cortisol and corticosterone) (8). In epithelial tissues, as well as in endothelial cells (9) and smooth muscle cells (10), the enzyme 11b-hydroxysteroid dehydrogenase type 2 (11HSD2) is able to convert endogenous glucocorticoids to inactive metabolites (11), promoting MR activation by aldosterone. In non-epithelial tissues, where expression of 11HSD2 is virtually absent or extremely low, such as brain, cardiomyocytes, and adipose tissue, glucocorticoids represent the major ligand of the MR (12).

Aging is a universal and independent risk factor for cardiovascular diseases (CVD) including hypertension, coronary artery disease, congestive heart failure and stroke $(13,14)$. According to a report from the American Heart Association (15), the incidence and prevalence of CVD significantly increases with age, and about two-thirds of CVD deaths occur in people aged 75 and older. To date, the influence of aging on aldosterone secretion and function in humans is not well-characterized, and the specific role of MR activation in vascular aging still awaits demonstration. In animal models, MR contributes to rising blood pressure with aging by regulating myogenic tone, vasoconstriction, and vascular oxidative stress (16). Both oxidative stress (17) and inflammation (18) are key factors in the pathophysiology of age-related cardiovascular disease in humans. Telomeres length in white blood cells can be considered as a biomarker of oxidative stress and inflammation as their progressive attrition, due to cell replication, is increased by oxidative stress, and inflammation determines an increase in white blood cells turnover rate. White blood cells telomeres are shorter in CVD patients. Aldosterone is known to accelerate cardiovascular aging through processes that generate reactive oxygen species in several tissues as well as in white blood cells (19-22) and an inverse relationship between circulating aldosterone and white blood cells telomeres length has been documented in normotensive aged matched men (23).

Several recent studies showed that MR expression is increased in vascular smooth muscle cells of aged animals $(24,25)$. Molecular mechanisms have also been uncovered by which rising vascular smooth muscle cell MR contributes to increased vasoconstriction with aging (26). Moreover, recent histopathologic findings have clarified profound alterations of the zona glomerulosa in adrenal glands with aging, which together with the increased vascular MR expression, may provide a further explanation for enhanced cardiovascular risk in the elderly $(27,28)$.

In this review, we will focus on the age-related alterations of MR signaling and aldosterone secretion and will discuss their specific role in determining increased cardiovascular risk in the elderly. Finally, we will address the potential relevance of MR pharmacological antagonism in the elderly, in order to increase arterial compliance and prevent cardiovascular aging and the associated morbidity and mortality.

\section{RAAS ALTERATIONS WITH AGING}

Several studies have shown that older healthy individuals display a reduction in renin-angiotensin-aldosterone system (RAAS) activity, with decreased plasma renin activity and lower levels of plasma renin and aldosterone under basal conditions (hyporeninaemic hypoaldosteronism) (29-33). The decline in plasma renin with age has been attributed to the effect of age-associated nephrosclerosis (34). Human studies with small sample sizes suggested that older individuals secrete less aldosterone than younger ones (35), resulting in a greater risk for hyperkalemia in older individuals (36), especially when coupled with the age-associated decline in glomerular filtration rate (GFR). Accordingly, renin synthesis and release gradually decrease in aging rats, resulting in lower levels of plasma renin (37). Moreover, older subjects also show an impaired ability to trigger adequate responses to RAAS stimuli, such as orthostatic hypotension, potassium infusion or sodium depletion $(29,38)$.

These age-related RAAS alterations have been attributed to different mechanisms occurring with aging, namely: (i) glomerulosclerosis and reduction in functional nephrons (3941); (ii) impaired function of juxtaglomerular apparatus (e.g., reduced sympathetic stimulation of the juxtaglomerular apparatus) (39); (iii) reduced renal production of kallikrein (a serine protease contributing to the synthesis of active renin); and (iv) reduced angiotensinogen synthesis by the liver $(39,42)$.

Importantly, age-related changes in RAAS activity lead older individuals to reduced ability to reabsorb sodium and reduced renal tubular potassium excretion, resulting in higher risk for volume depletion, hyponatremia and/or hyperkalemia (36). Of note, the risk for hyperkalemia is further enhanced under specific conditions, such as metabolic acidosis, reduction in GFR, or use of drugs inhibiting renal tubular potassium excretion [i.e., angiotensin converting enzyme (ACE) inhibitors, angiotensin II (Ang II) type 1 (AT1) receptor antagonists, MR antagonists, non-steroidal anti-inflammatory drugs (43)].

Recent reports clarified the histopathological changes occurring in adrenal glomerulosa cells with aging (27). The development of specific antibodies against aldosterone synthase (CYP11B2-the enzyme required for the final step of aldosterone production) recently allowed the detection of non-neoplastic foci of CYP11B2-expressing cells in the adrenal, referred to as aldosterone-producing cell clusters (APCC), which are commonly observed in normal human adrenals. Interestingly, recent studies revealed that the classic continuous CYP11B2 expression pattern within adrenal zona glomerulosa is gradually 
lost with aging, whereas accumulation of APCC in adrenal glands is frequently observed with advancing age. A direct evidence that APCC autonomously secrete aldosterone still awaits demonstration; however, aging is characterized by the transition from a physiological aldosterone regulation to a pattern of renin-independent aldosterone secretion, which could be sustained by increased number in APCC (28), and may account, at least in part, for the increased cardiovascular risk observed in the elderly (27).

Finally, it has been also shown that aging is associated with a decline in 11HSD2 activity, which results in renin suppression and cortisol-mediated MR activation (44), thus providing another potential mechanism for enhanced $\mathrm{MR}$ activation with aging.

Together, previous studies from both humans and animals provide evidence of altered RAAS activity and secretion with aging, which play a pivotal role in pathogenesis of CVD.

\section{ROLE OF THE MINERALOCORTICOID RECEPTOR IN VASCULAR DYSFUNCTION WITH AGING}

Aging is associated with structural, mechanical and functional alterations in the vasculature that are characterized by augmented vasoconstriction, reduced elasticity and distensibility, vascular stiffening, and impaired endothelial function (14, 45). These aging-related vascular changes contribute to cardiovascular disease and may be reversible; therefore, elucidating the mechanisms driving vascular aging has substantial potential to identify new therapeutic targets to prevent or reverse vascular aging, thereby attenuating the high CVD burden in the rapidly growing elderly population.

In addition to the traditional role of renal $\mathrm{MR}$ in regulating blood pressure by promoting sodium retention in the kidney (46), accumulated data in the past two decades indicate that $\mathrm{MR}$ is also expressed in the vasculature, including the smooth muscle cells, that contribute to vascular structure and vasoconstriction, and the endothelial cells, that contribute to barrier function and inflammation and thrombosis when injured $(9,10,26)$. Substantial evidence support that MR in vascular cells contributes to CVD [reviewed elsewhere $(47,48)]$. Animal studies have demonstrated that treatment with MR antagonists ameliorates vascular remodeling and dysfunction in the setting of CVD risk factors, including aging, western diet-induced obesity and hypertension, without significantly altering blood pressure (49-52), suggesting direct effects of MR antagonism on the vasculature. In clinical studies, MR antagonist treatment reduced vascular stiffness in elderly patients particularly with hypertension $(53,54)$.

MR expression increases in the vasculature with aging. Krug et al. found that MR gene expression is higher in aortas from aged rat (30 months of age) than in aortas from adult rat (8 months of age), and that MR protein expression was increased with aging in isolated rat aortic smooth muscle cells (24). More recent studies have similarly shown increased MR gene expression in mouse mesenteric resistance arteries with aging
(25). To investigate the specific role for vascular smooth muscle cells MR in age-related mechanical and functional changes in the vasculature with aging, mice with smooth muscle cell-specific deficiency of MR (SMC-MR-KO) have been generated (26). Using these mice, McCurley et al. found that the moderate rise in blood pressure with aging in mice is prevented in SMCMR-KO mice, without defects in renal function. Compared to aged MR-intact mice, 12 month-old SMC-MR-KO mice also showed decreased myogenic tone, vasoconstriction, and voltagegated calcium channel expression, and decreased oxidative stress both at baseline and in response to Ang II (26). These findings indicate a direct contribution of smooth muscle cells-MR to increased vasoconstriction, vessel tone, and oxidative stress in aging vessels, which may contribute to the inexorable rise in blood pressure with aging. Further exploration of the mechanism by unbiased global miRNA expression profiling in mouse aortas, identified microRNA (miR)-155 as the most down-regulated miRNA in the aging vasculature. Interestingly, such downregulation was prevented in SMC-MR-KO mice (25). DuPont et al. further demonstrated that MR transcriptionally represses the miR-155 host gene promoter. Thus, the increase in vascular MR expression with aging was associated with repression of miR155 and increased expression of miR-155 target genes including the L-type calcium channel (LTCC) subunit Cav1.2 and the Ang II type 1 receptor (Agtr1), which are known to contribute to vasoconstriction and vascular oxidative stress with aging. These aging effects were prevented in SMC-MR-KO mice further supporting this as a mechanism by which smooth muscle cellsMR contributes to increased vasoconstriction, vessel tone and oxidative stress during aging (25).

Smooth muscle cells-MR was also recently found to contribute to vascular structural changes with aging that determine vascular stiffening (16), a prominent consequence of aging in humans that correlates with risk of cardiovascular events (14, 45, 55). Although multiple CVD risk factors accelerate vascular stiffening, aging itself is associated with vascular stiffening that can occur independently and may even contribute to the development of other risk factors including hypertension (5557). An important cause of vascular stiffness is excessive vascular fibrosis and reduced elasticity (45). Comparison of vascular stiffness with aging in MR-intact mice revealed increased aortic stiffness in 12 month- and 18 month-old mice compared to 3 month-old mice, along with increased fibrosis in aorta, carotid arteries and renal arterioles. These aging-associated increases in vascular stiffness and fibrosis were mitigated in SMC-MR-KO mice (16). Gene expression profiling in aortas revealed that MR deletion in smooth muscle cells induces a distinct anti-fibrotic gene profile in the aging vasculature, including downregulation of well-characterized pro-fibrotic genes such as connective tissue growth factor (CTGF), matrix metalloprotease-2 (MMP2), and bone morphogenetic protein-4 (BMP4) (16), that contribute to vascular fibrosis $(14,45)$. These findings indicate a role for smooth muscle cell-MR in vascular aging as a transcriptional regulator that activates pro-fibrotic genes with aging, consistent with prior studies showing that aldosterone activates pro-fibrotic genes in mouse vessels (58) and in human coronary artery smooth muscle cells (10). Moreover, long-term treatment of aged 
mice with MR antagonist prevented the progression of vascular stiffening, reduced vascular fibrosis and induced a similar antifibrotic gene signature as smooth muscle cell-MR gene deletion (16). A small cohort study in humans also showed that MR antagonism treatment for 1 month reduced fibrotic biomarkers in the serum from elderly patients compared to placebo treatment (16). Altogether, the available preclinical data reveal that MR expression in smooth muscle cells of the vasculature increases with aging and induces structural, mechanical, and functional changes in vessels that contribute to vascular stiffness and to rising blood pressure with age (Figure 1). Mechanistically, smooth muscle cell-MR contributes to functional and structural alterations of vessels with aging through the role of MR as a transcriptional regulator of genes associated with vascular tone, oxidative stress and fibrosis. Although larger and longer clinical studies in elderly humans are warranted, these findings support the potential benefits of MR antagonism to treat vascular aging and associated morbidity with aging.

To our knowledge, the specific role of MR in other vascular cells, such as endothelial cells, myeloid cells, fibroblasts, or perivascular adipose cells, has not been directly investigated in the setting of aging. However, studies have demonstrated that endothelial cell-specific MR deficiency or MR antagonists treatment in mice prevents hormone- or diet-induced increases

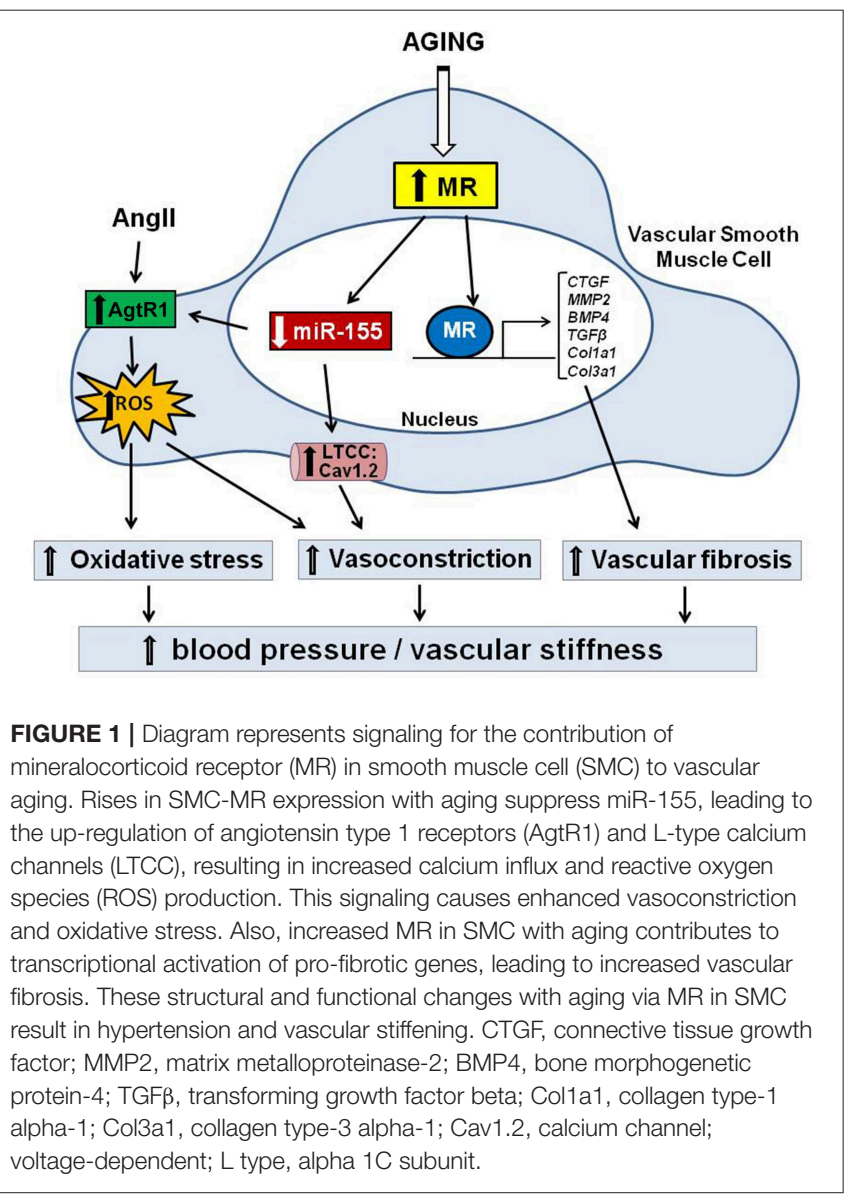

in endothelial cell stiffness, oxidative stress, leukocyte adhesion and the associated decrease in nitric oxide (NO) production $(59,60)$, which are prominent features of age-related vascular dysfunction (48). In addition, although smooth muscle cell MR does not contribute to atherosclerosis (61), endothelial cell MR has recently been implicated in vascular inflammation in mouse models of atherosclerosis, specifically in males (62). Prior studies have also implicated MR expressed by myeloid cells in atherosclerosis, in vascular inflammation, fibrosis and remodeling as well as T-cell MR in hypertension (63-65). Thus, MR in other cells contributes to important vascular phenotypes that are known to be associated with vascular aging, supporting the need for future studies to investigate directly the roles for non-smooth muscle cells MR in vascular aging.

\section{ROLE OF MINERALOCORTICOID RECEPTOR IN MYOCARDIAL DYSFUNCTION WITH AGING}

The aging heart is characterized by various functional and structural changes, partially resembling some of the features observed in animal models of increased MR activation (66), such as inflammation, oxidative stress, collagen accumulation and fibrotic remodeling (66-68). A growing body of evidence has suggested an important contribution of aldosterone and MR activation to cardiac remodeling and heart failure (69, 70). MR expression was first detected in cardiomyocytes and endothelial cells of atria and ventricles almost 30 years ago (71). In the myocardium, MR is also expressed in cell types other than cardiomyocytes, including coronary vasculature and macrophages $(71,72)$. Interestingly, experimental studies have shown that mice with cardiomyocyte-specific overexpression of MR display oxidative stress-mediated coronary endothelial dysfunction and increased expression of pro-fibrotic markers (e.g., CTGF) $(67,69,73)$. Wilson et al. demonstrated that rats exposed to mineralocorticoids excess undergo a series of inflammatory and oxidative stress responses before the onset of myocardial hypertrophy or fibrosis (74). A recent publication by Kim et al. indicates that smooth muscle cell-MR deletion attenuates aging-associated increases in cardiac stiffness. The increase in cardiac systolic stiffness with aging correlated with the degree of aortic stiffness, suggesting that cardiac benefits of smooth muscle cell MR deletion in mice may be secondary to the prevention of vascular stiffening (16).

Macrophage MR has been also found to play a key role in mediating cardiac tissue remodeling, stimulating the pro-inflammatory macrophage M1-like phenotype (known as "classically activated" macrophages) and regulating the transcription of different inflammatory and pro-fibrotic markers, such as tumor necrosis factor $\alpha$ (TNF $\alpha$ ) and transforming growth factor $\beta 1$ (TGF- $\beta 1)(68,75)$. MR is also expressed on T lymphocytes and its overactivation upregulates CD8+ cytotoxic $\mathrm{T}$ cells and $\mathrm{T}$ helper 17 (Th17) cells infiltrating in the heart. Other studies showed that MR antagonism decreases Th17 polarization and induces the T regulatory cells phenotype (76, 77). Interestingly, pharmacological MR antagonism decreased 
the accumulation and activation of CD4+ and CD8 $+\mathrm{T}$ cells in the murine heart and $\mathrm{T}$ cells specific MR-knockout mice displayed reduced cardiac hypertrophy, fibrosis, and dysfunction (78). Moreover, the MR selective antagonist eplerenone improved the adverse cardiac effects of aging in spontaneously hypertensive rats, reducing myocardial fibrosis and improving left ventricular diastolic function and coronary hemodynamics (79).

MR activation can also affect myocardial electrical function, potentially causing lethal cardiac arrhythmias associated with heart failure $(70,80)$. Gómez et al. demonstrated that the overstimulation of cardiac MR pathway leads to increased ryanodine receptor activity and long-lasting and broader spontaneous calcium sparks, which potentially predispose to arrhythmias (81). Another study has shown that transgenic mice with cardiac-selective overexpression of human MR exhibit a high rate of death due to ion channel remodeling (reduced outward $\mathrm{K}^{+}$transient current, increased $\mathrm{Ca}^{2+}$ influx), which results in prolonged ventricular repolarization and fatal ventricular arrhythmias in absence of structural cardiac defects. Importantly, administration of spironolactone in pregnant mice was able to prevent embryonic and postnatal death in the offspring, suggesting that offspring lethality was highly related to MR overexpression and activation (82).

Atrial fibrillation is the most frequent cardiac arrythmias in the elderly population (83). Interestingly, Tsai et al. found that atrial MR expression is significantly higher in patients with atrial fibrillation compared with individuals with normal sinus rhythm. In the same study, aldosterone increased the expression of $\alpha$ $1 \mathrm{G}$ and- $1 \mathrm{H}$ subunits of the T-type calcium channel in cultured murine HL-1 atrial myocytes, leading to increased T-type calcium current and calcium overload, which was attenuated by the mineralocorticoid antagonist spironolactone (84). Accordingly, although there is no evidence showing a direct role of MR dysfunction in aging causing atrial fibrillation, we can speculate that increased MR signaling in heart tissue, due to aging, could represent a causal link between aging and atrial fibrillation. Further studies are needed to directly explore this possibility.

In summary, accumulating data demonstrate that $\mathrm{MR}$ contributes to aging-associated myocardial dysfunction with cell type-dependent mechanisms revealed by animal studies, thus supporting the potential benefits of MR antagonism to treat cardiac dysfunction, especially in elderly population.

\section{ROLE OF MINERALOCORTICOID RECEPTOR IN ENDOTHELIAL DYSFUNCTION AND INFLAMMATION WITH AGING}

Very little is known about the role of aldosterone and MR activation in the vasculature in the context of healthy human aging. Healthy endothelial cells secrete vasodilator mediators which activate signaling pathways inducing smooth muscle cells to relax and leading to vasodilation (85). Nitric oxide (NO) is produced by healthy ECs after activation of endothelial nitric oxide synthase (eNOS). NO represents a major mediator of endothelial-dependent vasorelaxation $(86,87)$. In patients with cardiovascular risk factors, such as hypertension, obesity and diabetes, extensive data demonstrate that MR activation contributes to endothelial dysfunction, through impairment of vasodilation induced by the endothelium $(22,85,88-91)$. In human coronary endothelial cells, MR regulates several genes involved in inflammation and oxidative stress $(9,10)$. It is known that MR activation in endothelial cells contributes to cardiac inflammation and remodeling by promoting the expression of vascular cell adhesion molecule 1 (VCAM1), as shown in animal models of hypertension (92). Moreover, aldosterone-mediated endothelial MR activation leads to the overexpression of the intracellular adhesion molecule-1 (ICAM-1), thereby enhancing leukocyte adhesion to coronary artery endothelial cells $(9,93)$. In vivo, MR in the endothelium contributes to ICAM-1 and Eselectin expression thereby contributing to leukocyte slow rolling and adhesion to the vasculature, a critical step in the process of inflammation (62).

Reactive oxygen species have also been suggested to mediate the detrimental effects of aldosterone in the vasculature through MR activation $(94,95)$. Arterial superoxide levels increase with aging, in part because of the excessive activity of NADPH oxidase. Increased oxidative stress leads to the inactivation of nitric oxide (96) and consequent arterial stiffness (97). Several studies showed that MR activates NADPH oxidase-dependent superoxide production $(22,90)$ and MR blockade decreases NADPH oxidase activity, reduces superoxide formation, and improves nitric oxide bioavailability (98). Importantly, the sensitivity of the MR to aldosterone is enhanced in arteries from aged and/or hypertensive humans (99). In animal models with enhanced cardiovascular risk, endothelial dysfunction is driven by aldosterone activation of endothelial cell-MR. Spironolactone significantly improved endothelial function in middle cerebral artery in a spontaneously hypertensive rat model (100). Moreover, pharmacological MR inhibition or selective deletion of MR in endothelial cells prevented impaired vasodilation in a model of diet-induced obesity (101) specifically in females (102). Finally, selective endothelial cell MR deletion in mice improved endothelial dysfunction upon a challenge of Ang II induced hypertension (103).

Only few clinical studies evaluated the effects of MR antagonists on arterial stiffness in hypertensive patients. In two different studies, eplerenone showed higher efficacy in reducing arterial stiffness than atenolol and a thiazide type diuretic $(53,104)$. On the other hand, a study comparing eplerenone and amlodipine showed that the aortic pulse wave velocity decreased similarly in both groups (105). Interestingly, in a randomized study conducted by Hwang et al. on healthy older adults free from overt cardiovascular disease, pharmacological inhibition of MR did not decrease oxidative stress nor lead to improved arterial stiffness and wave reflections. These findings suggest that MR may not substantially contribute to oxidative stress in healthy human aging in the absence of additional risk factors (106). The same authors also showed that acute inhibition of $\mathrm{MR}$ in healthy aged adults led to impairments in vascular endothelial function, suggesting that the MR may induce beneficial physiological actions in regulating eNOS activity and flow-mediated endothelium-dependent dilation in healthy aging 
(107). Vascular smooth muscle responsiveness to exogenous nitric oxide was not influenced by acute MR antagonism in this population. Similarly, acute MR antagonism did not affect systemic blood pressure or circulating and endothelial cell markers of oxidative stress and inflammation (107). Other studies demonstrated that MR deletion in endothelial cells does not inhibit endothelium-dependent relaxation in healthy aorta (101), mesentery and coronary arteries (103). Conversely, in subjects with CVD risk factors, endothelial dysfunction seems to be dependent on MR activation. In this regard, studies conducted in animal models suggest that the specific role of MR activation in endothelial function depends on endothelial health and integrity (102, 108). Thus, it can be speculated that MR activation determines the induction of a vasodilatory response in healthy endothelium, and a vasoconstriction response (potentially mediated by smooth muscle cell-MR) when the endothelium is stressed or damaged.

Aging is associated with a progressive worsening of several physiological processes, leading to an increased risk of diseases, particularly at cardiovascular level $(13,14)$. Aging causes a proinflammatory state, remodeling of the vasculature, endothelial dysfunction and excessive production of reactive oxygen species $(13,14,96,109)$, mainly by increased expression and activity of $\mathrm{NAD}(\mathrm{P}) \mathrm{H}$ oxidase, which is not efficiently countered by antioxidant enzymes $(110,111)$. In the elderly, oxidative stress represents the most important cause of epigenetic modification (112) of the genes encoding for the antioxidant enzyme superoxide dismutase (113). In addition, the increased endoplasmic reticulum stress and proteasome activity elicits the process of unfolded protein response in vascular smooth muscle cells, monocytes, and endothelial cells (114). In this particular context of unhealthy aging, characterized by vascular damage, endothelial cell-MR activation can amplify cardiovascular adverse outcomes, exacerbating vascular stiffness through the induction of augmented reactive oxygen species production, collagen deposition, and vascular inflammation (9, 94, 95), resulting in altered vasodilation, endothelial dysfunction, and atherosclerosis (Figure 2).

In summary, a large body of evidence indicate that endothelial cell-MR is implicated in the pathological outcomes of cardiovascular risk factors, which are also highly associated with aging. Future studies are needed to determine if endothelial cellMR plays a direct role in cardiovascular aging in animal models and humans.

\section{MR ANTAGONISTS IN THE ELDERLY: CLINICAL STUDIES}

MR antagonists are largely used for the treatment of resistant hypertension and hearth failure (HF) (115), which represent highly prevalent diseases among older individuals $(116,117)$. In this context, several clinical trials demonstrated that cardiovascular morbidity and mortality are significantly reduced from the use of MR antagonists in moderate to severe heart failure with reduced ejection fraction (HFrEF) (118-120). In the double-blind Randomized Aldactone Evaluation Study (RALES), 1,663 patients with severe HFrEF and an average age of 65

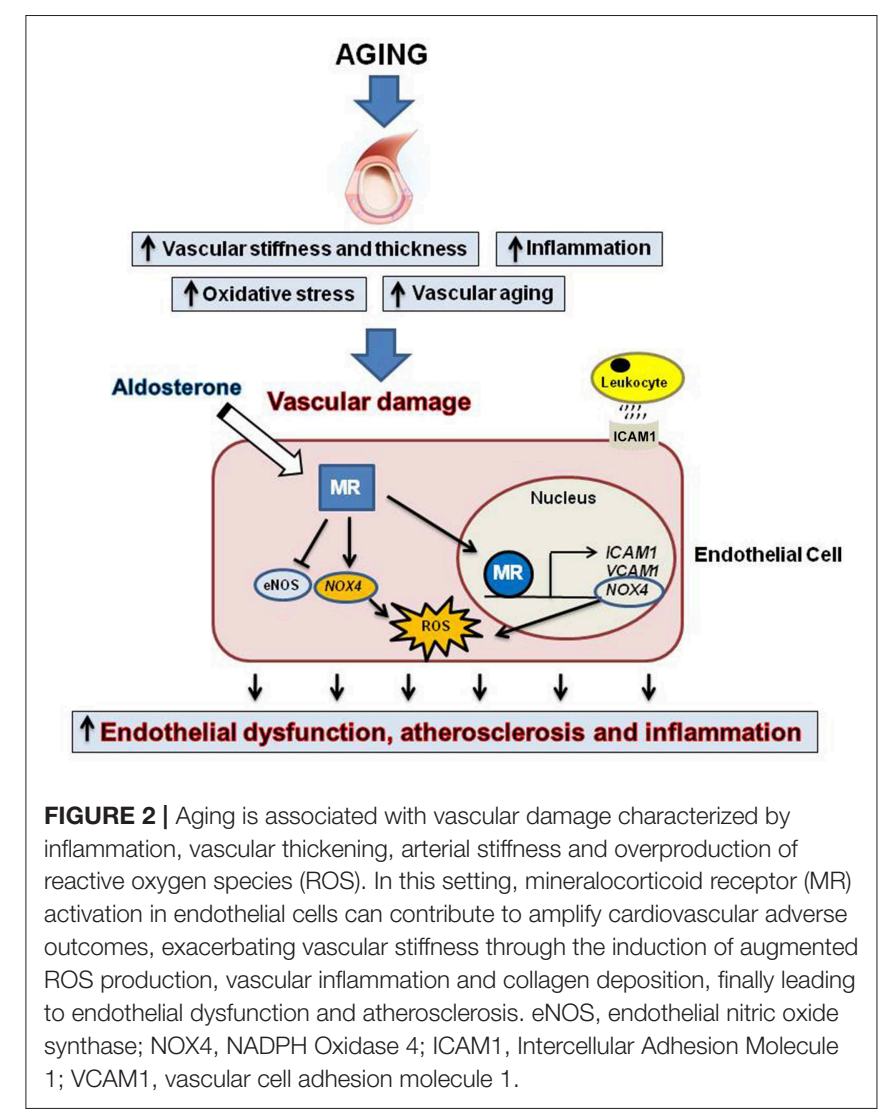

years were randomly assigned to receive the MR antagonist spironolactone or placebo. After a mean follow-up period of 24 months, individuals from the spironolactone group showed a significant improvement in the symptoms of heart failure and a significant reduction in mortality, the latter attributed to the lower risk of death from cardiac causes (118). Thereafter, the Eplerenone Post-AMI Heart Failure Efficacy and Survival Study (EPHESUS) investigated the effects of the selective MR antagonist eplerenone on morbidity and mortality among 6,642 patients with an average age of 64 years and HFrEF following an acute myocardial infarction. After a mean follow-up period of 16 months, eplerenone significantly reduced the risk of death and hospitalization from cardiovascular causes and from any cause, as well as the rate of sudden death from cardiac causes (120). In contrast with these findings, the Treatment of Preserved Cardiac Function Heart Failure with an Aldosterone Antagonist trial (TOPCAT) found that spironolactone did not significantly reduce the rates of the primary composite outcome of death from cardiovascular causes, cardiac arrest, or hospitalization for heart failure in patients with heart failure with preserved ejection fraction (HFpEF) and a median age of 68.7 years (121). However, a post-hoc analysis has shown that spironolactone significantly reduced the TOPCAT primary outcome in patients with HFpEF from the Americas, suggesting that differences in demographic characteristics among recruited individuals may have represented a relevant bias of the study (122). On the other hand, a meta-analysis of seven randomized controlled trials evaluating the impact of MR antagonists on cardiovascular mortality and morbidity outcomes in patients with heart failure 
and/or left ventricular systolic dysfunction aged $\geq 65$ years, did not confirm significant improvement in clinical outcomes among patients with HFpEF. However, the same study showed that MR antagonism improves clinical outcomes in selected cohorts of older patients with HFrEF (123). Another sub-analysis, which included 1,767 of the TOPCAT patients and was equally comprised of men and women, demonstrated that women with HFpEF had a significant reduction in cardiovascular and allcause mortality with spironolactone, while men did not (124).

Interestingly, MR antagonists were also found to exert clinical benefit in patients with atrial fibrillation. In particular, a clinical trial on 164 patients aged $\geq 66$ years with recurring atrial fibrillation showed that spironolactone, administered with $\beta$ blockers, was able to significantly prevent arrhythmic events, compared to spironolactone untreated patients (125). Recently, a retrospective cohort study of the contemporary ORBIT-AF (Outcomes Registry for Better Informed Treatment of Atrial Fibrillation) registry showed that the use of MR antagonists was not associated with reduced atrial fibrillation, but showed a trend toward lower risk of stroke, transient ischemic attack, or systemic embolism (126). However, the hypothesis that MR antagonists therapy may reduce residual stroke risk in patients with atrial fibrillation awaits demonstration in randomized clinical trials.

The recent 2018 ESC/ESH guidelines for the management of arterial hypertension now recommend that systolic blood pressure should be targeted to a range of $130-139 \mathrm{mmHg}$ in older ( $>65$ years) and very old ( $>80$ years) patients (127). Importantly, recommended treatment of resistant hypertension considers the addition of low-dose spironolactone (up to $50 \mathrm{mg}$ /day) to existing therapy also in the elderly population, where loop diuretics and alpha-blockers should be avoided due to their association with falls (128), extending the possibility of pharmacological MR antagonism in the aging hypertensive population.

In light of the significant cardiovascular benefits of $\mathrm{MR}$ antagonism in the aging population, their use in clinical setting is limited by the adverse effects induced by MR blockade on the kidney, such as hyperkalemia, particularly in older patients with reduced renal function and by their anti-androgenic properties (particularly exhibited by spironolactone) which can induce gynecomastia and erectile dysfunction in men $(129,130)$. Therefore, the current use of MR antagonists is restricted to patients with an estimated glomerular filtration rate $>45 \mathrm{~mL} / \mathrm{min}$ and a plasma potassium concentration of $<4.5 \mathrm{mmol} / \mathrm{L}$, in order to avoid the risk of hyperkalaemia (127). For such reasons, there is an unmet need for the development of more selective MR antagonist for heart and vasculature, in order to minimize the relevant side effects on non-cardiac tissues.

\section{CONCLUDING REMARKS}

It is now clear that altered MR function is involved in the pathophysiology of endothelial dysfunction, atherosclerosis, oxidative stress, and cardiac remodeling. Altogether, these conditions are highly prevalent in the aging population and are deeply involved in the development of ischemic events and heart failure, common causes of morbidity and death in the elderly.
Several recent studies demonstrated that aging is associated with important alterations in the aldosterone-MR system with changes in aldosterone production by the aging adrenal and increased MR responsiveness by the aging cardiovascular system. In accordance, clinical trials revealed the efficacy of MR antagonism in improving cardiovascular morbidity and decreasing mortality. The mechanisms involved in these cardiovascular benefits are complex and well beyond their well-known blood pressure lowering effects. It is now clear that systemic pharmacological antagonism produces direct effects in the vasculature and heart. However, MR pharmacological blockade in clinical practice has been limited by the risk of important adverse effects, such as hyperkalemia and renal dysfunction worsening, which is particularly frequent in aged individuals. Recently, a novel class of non-steroidal MR antagonist has been developed (131). Finerenone belongs to this group of molecules and its MR selectivity and affinity are higher compared to spironolactone and eplerenone. Due to these differences, finerenone may potentially reduce risk of both hyperkalaemia and renal impairment and, if so, may be safer to use in patients with heart failure affected by chronic renal dysfunction (132). Specifically, five phase II clinical trials demonstrated that finerenone is safe in patients with heart failure and concomitant chronic renal impairment and/or diabetes mellitus, and neither hyperkalemia nor reductions in kidney function were limiting factors to its use in over two thousand patients (133). Such favorable side effects profile is reached in the presence of similar clinical efficacy compared to other MR antagonists. Importantly, the addition of finerenone in patients with diabetic nephropathy resulted in improvement in the urinary albumin-creatinine ratio (134). ARTS-HF was the first clinical trial to compare finerenone with eplerenone, in patients with worsening HFrEF and chronic kidney disease and/or diabetes mellitus, with a mean age of 71.5 years. In such vulnerable population, finerenone reduced levels of NT-proBNP to a similar extent to that of eplerenone, but showed less changes in serum potassium from baseline to the end of the study in comparison to eplerenone (135). Importantly, finerenone at a dose of 10-20 mg demonstrated a nominally improved outcome of a composite clinical endpoint of death from any cause, $\mathrm{CV}$ hospitalizations, or emergency presentation for worsening heart failure (hazard ratio, HR: 0.56 [95\% CI: 0.35-0.90]) compared to eplerenone in ARTS-HF. Moreover, preclinical studies showed that finerenone was able to potently block cardiac fibrosis and macrophages infiltration in a mouse model of isoproterenolinduced cardiac fibrosis, whereas eplerenone did not show significant effects (136). Nevertheless, phase III clinical trials will be crucial to further investigate the efficiency and safety of novel MR antagonists in the aging population, and studies on different subgroups of elderly people will help to identify new strategies to prevent cardiovascular aging, and to reduce the risk of end-organ damage related to MR activation (137).

\section{AUTHOR CONTRIBUTIONS}

SG and SK conceived and wrote the manuscript. MI wrote, in part, and revised the manuscript. CM prepared the figures and 
revised the manuscript. SL, AF, and IJ revised the manuscript. $\mathrm{MC}$ conceived, wrote, in part, and revised the manuscript.

\section{FUNDING}

This work was supported, in part, by a grant from Ministero della Salute (Ricerca Corrente), by the European Research Area Network (ERA-Net PREMED-CAD), a grant of MIUR

\section{REFERENCES}

1. Funder JW. Mineralocorticoid receptors: distribution and activation. Heart Fail Rev. (2005) 10:15-22. doi: 10.1007/s10741-005-2344-2

2. Bridgham JT, Carroll SM, Thornton JW. Evolution of hormone-receptor complexity by molecular exploitation. Science. (2006) 312:97-101. doi: 10.1126/science. 1123348

3. Danziger J, Zeidel ML. Osmotic homeostasis. Clin J Am Soc Nephrol. (2015) 10:852-62. doi: 10.2215/CJN.10741013

4. Fu Y, Vallon V. Mineralocorticoid-induced sodium appetite and renal salt retention: evidence for common signaling and effector mechanisms. Nephron Physiol. (2014) 128:8-16. doi: 10.1159/000368264

5. Atlas SA. The renin-angiotensin aldosterone system: pathophysiological role and pharmacologic inhibition. J Manag Care Pharm. (2007) 13(Suppl. B):9-20. doi: 10.18553/jmcp.2007.13.s8-b.9

6. Shibata S. Context-dependent mechanisms modulating aldosterone signaling in the kidney. Clin Exp Nephrol. (2016) 20:663-70. doi: 10.1007/s10157-016-1232-5

7. Funder JW. Aldosterone and mineralocorticoid receptors-physiology and pathophysiology. Int J Mol Sci. (2017) 18:E1032. doi: 10.3390/ijms18051032

8. Arriza JL, Weinberger C, Cerelli G, Glaser TM, Handelin BL, Housman DE, et al. Cloning of human mineralocorticoid receptor complementary DNA: structural and functional kinship with the glucocorticoid receptor. Science. (1987) 237:268-75. doi: 10.1126/science.3037703

9. Caprio M, Newfell BG, la Sala A, Baur W, Fabbri A, Rosano G, et al. Functional mineralocorticoid receptors in human vascular endothelial cells regulate intercellular adhesion molecule-1 expression and promote leukocyte adhesion. Circ Res. (2008) 102:1359-67. doi: 10.1161/CIRCRESAHA.108.174235

10. Jaffe IZ, Mendelsohn ME. Angiotensin II and aldosterone regulate gene transcription via functional mineralocortocoid receptors in human coronary artery smooth muscle cells. Circ Res. (2005) 96:643-50. doi: 10.1161/01.RES.0000159937.05502.d1

11. Edwards CR, Stewart PM, Burt D, Brett L, McIntyre MA, Sutanto WS, et al. Localisation of 11 beta-hydroxysteroid dehydrogenase-tissue specific protector of the mineralocorticoid receptor. Lancet. (1988) 2:986-9. doi: 10.1016/S0140-6736(88)90742-8

12. Marzolla V, Armani A, Feraco A, De Martino MU, Fabbri A, Rosano $\mathrm{G}$, et al. Mineralocorticoid receptor in adipocytes and macrophages: a promising target to fight metabolic syndrome. Steroids. (2014) 91:46-53. doi: 10.1016/j.steroids.2014.05.001

13. Lakatta EG, Levy D. Arterial and cardiac aging: major shareholders in cardiovascular disease enterprises: part I: aging arteries: a "set up" for vascular disease. Circulation. (2003) 107:139-46. doi: 10.1161/01.CIR.0000048892.83521.58

14. Lakatta EG. Arterial and cardiac aging: major shareholders in cardiovascular disease enterprises: part III: cellular and molecular clues to heart and arterial aging. Circulation. (2003) 107:490-7. doi: 10.1161/01.CIR.0000048894.99865.02

15. Mozaffarian D, Benjamin EJ, Go AS, Arnett DK, Blaha MJ, Cushman $\mathrm{M}$, et al. Heart disease and stroke statistics-2015 update: a report from the American Heart Association. Circulation. (2015) 131:e29-322. doi: 10.1161/CIR.0000000000000152

16. Kim SK, McCurley AT, DuPont JJ, Aronovitz M, Moss ME, Stillman IE, et al. Smooth muscle cell-mineralocorticoid receptor as a mediator
(Progetti di Ricerca di interesse Nazionale 2015- project code 2015ZTT5KB - to MC, Work Package Leader), and a grant from the National Institutes of Health (HL119290 to IJ).

\section{ACKNOWLEDGMENTS}

We wish to thank Dr. Peter Kolkhof for critical reading of the manuscript. of cardiovascular stiffness with aging. Hypertension. (2018) 71:609-21. doi: 10.1161/HYPERTENSIONAHA.117.10437

17. Stocker R, Keaney JF. Role of oxidative modifications in atherosclerosis. Physiol Rev. (2004) 84:1381-478. doi: 10.1152/physrev.00047.2003

18. Granger DN, Vowinkel T, Petnehazy T. Modulation of the inflammatory response in cardiovascular disease. Hypertension. (2004) 43:924-31. doi: 10.1161/01.HYP.0000123070.31763.55

19. Pu Q, Neves MF, Virdis A, Touyz RM, Schiffrin EL. Endothelin antagonism on aldosterone-induced oxidative stress and vascular remodeling. Hypertension. (2003) 42:49-55. doi: 10.1161/01.HYP.0000078357. 92682.EC

20. Park SK, Kim GY, Lim JY, Kwak JY, Bae YS, Lee JD, et al. Acidic polysaccharides isolated from Phellinus linteus induce phenotypic and functional maturation of murine dendritic cells. Biochem Biophys Res Commun. (2003) 312:449-58. doi: 10.1016/j.bbrc.2003.10.136

21. Nishiyama A, Yao L, Nagai Y, Miyata K, Yoshizumi M, Kagami S, et al. Possible contributions of reactive oxygen species and mitogen-activated protein kinase to renal injury in aldosterone/salt-induced hypertensive rats. Hypertension. (2004) 43:841-8. doi: 10.1161/01.HYP.0000118519. 66430.22

22. Keidar S, Kaplan M, Pavlotzky E, Coleman R, Hayek T, Hamoud S, et al. Aldosterone administration to mice stimulates macrophage NADPH oxidase and increases atherosclerosis development: a possible role for angiotensinconverting enzyme and the receptors for angiotensin II and aldosterone. Circulation. (2004) 109:2213-20. doi: 10.1161/01.CIR.0000127949.05756.9D

23. Benetos A, Gardner JP, Kimura M, Labat C, Nzietchueng R, Dousset B, et al. Aldosterone and telomere length in white blood cells. J Gerontol A Biol Sci Med Sci. (2005) 60:1593-6. doi: 10.1093/gerona/60.12.1593

24. Krug AW, Allenhöfer L, Monticone R, Spinetti G, Gekle M, Wang M, et al. Elevated mineralocorticoid receptor activity in aged rat vascular smooth muscle cells promotes a proinflammatory phenotype via extracellular signal-regulated kinase 1/2 mitogen-activated protein kinase and epidermal growth factor receptor-dependent pathways. Hypertension. (2010) 55:147683. doi: 10.1161/HYPERTENSIONAHA.109.148783

25. DuPont JJ, McCurley A, Davel AP, McCarthy J, Bender SB, Hong K, et al. Vascular mineralocorticoid receptor regulates microRNA-155 to promote vasoconstriction and rising blood pressure with aging. JCI Insight. (2016) 1:e88942. doi: 10.1172/jci.insight. 88942

26. McCurley A, Pires PW, Bender SB, Aronovitz M, Zhao MJ, Metzger D, et al. Direct regulation of blood pressure by smooth muscle cell mineralocorticoid receptors. Nat Med. (2012) 18:1429-33. doi: 10.1038/nm.2891

27. Nanba K, Vaidya A, Williams GH, Zheng I, Else T, Rainey WE. Age-related autonomous aldosteronism. Circulation. (2017) 136:347-55. doi: 10.1161/CIRCULATIONAHA.117.028201

28. Nanba K, Vaidya A, Rainey WE. Aging and Adrenal Aldosterone Production. Hypertension. (2018) 71:218-23. doi: 10.1161/HYPERTENSIONAHA.117.10391

29. Weidmann P, De Myttenaere-Bursztein S, Maxwell MH, de Lima J. Effect on aging on plasma renin and aldosterone in normal man. Kidney Int. (1975) 8:325-33. doi: 10.1038/ki.1975.120

30. Noth RH, Lassman MN, Tan SY, Fernandez-Cruz A, Mulrow PJ. Age and the renin-aldosterone system. Arch Intern Med. (1977) 137:1414-7. doi: 10.1001/archinte.137.10.1414

31. Zakharieva S, Ankov V. [Renin-angiotensin-aldosterone system with regard to age]. Vutr Boles. (1982) 21:70-5. 
32. Bauer JH. Age-related changes in the renin-aldosterone system. Physiological effects and clinical implications. Drugs Aging. (1993) 3:238-45. doi: 10.2165/00002512-199303030-00005

33. Yoon HE, Choi BS. The renin-angiotensin system and aging in the kidney. Kor J Intern Med. (2014) 29:291-5. doi: 10.3904/kjim.2014.29.3.291

34. Turgut F, Balogun RA, Abdel-Rahman EM. Renin-angiotensin-aldosterone system blockade effects on the kidney in the elderly: benefits and limitations. Clin J Am Soc Nephrol. (2010) 5:1330-9. doi: 10.2215/CJN.08611209

35. Tsunoda K, Abe K, Goto T, Yasujima M, Sato M, Omata K, et al. Effect of age on the renin-angiotensin-aldosterone system in normal subjects: simultaneous measurement of active and inactive renin, renin substrate, and aldosterone in plasma. J Clin Endocrinol Metab. (1986) 62:384-9. doi: 10.1210/jcem-62-2-384

36. Epstein M, Hollenberg NK. Age as a determinant of renal sodium conservation in normal man. J Lab Clin Med. (1976) 87:411-7.

37. Jung FF, Kennefick TM, Ingelfinger JR, Vora JP, Anderson S. Downregulation of the intrarenal renin-angiotensin system in the aging rat. $J \mathrm{Am}$ Soc Nephrol. (1995) 5:1573-80.

38. Mulkerrin E, Epstein FH, Clark BA. Aldosterone responses to hyperkalemia in healthy elderly humans. J Am Soc Nephrol. (1995) 6:1459-62.

39. Belmin J, Lévy BI, Michel JB. Changes in the renin-angiotensinaldosterone axis in later life. Drugs Aging. (1994) 5:391-400. doi: 10.2165/00002512-199405050-00007

40. Anderson S, Brenner BM. Effects of aging on the renal glomerulus. Am J Med. (1986) 80:435-42. doi: 10.1016/0002-9343(86)90718-7

41. Kasiske BL. Relationship between vascular disease and age-associated changes in the human kidney. Kidney Int. (1987) 31:1153-9. doi: 10.1038/ki.1987.122

42. Sealey JE, Atlas SA, Laragh JH, Oza NB, Ryan JW. Human urinary kallikrein converts inactive to active renin and is a possible physiological activator of renin. Nature. (1978) 275:144-5. doi: 10.1038/275144a0

43. Zhou XJ, Saxena R, Liu Z, Vaziri ND, Silva FG. Renal senescence in 2008: progress and challenges. Int Urol Nephrol. (2008) 40:823-39. doi: 10.1007/s1 1255-008-9405-0

44. Campino C, Martinez-Aguayo A, Baudrand R, Carvajal CA, Aglony M, Garcia H, et al. Age-related changes in $11 \beta$-hydroxysteroid dehydrogenase type 2 activity in normotensive subjects. Am J Hypertens. (2013) 26:481-7. doi: 10.1093/ajh/hps080

45. Harvey A, Montezano AC, Lopes RA, Rios F, Touyz RM. Vascular fibrosis in aging and hypertension: molecular mechanisms and clinical implications. Can J Cardiol. (2016) 32:659-68. doi: 10.1016/j.cjca.2016.02.070

46. Rossier BC, Pradervand S, Schild L, Hummler E. Epithelial sodium channel and the control of sodium balance: interaction between genetic and environmental factors. Annu Rev Physiol. (2002) 64:877-97. doi: 10.1146/annurev.physiol.64.082101.143243

47. DuPont JJ, Jaffe IZ. 30 years of the mineralocorticoid receptor: the role of the mineralocorticoid receptor in the vasculature. J Endocrinol. (2017) 234:T67-82. doi: 10.1530/JOE-17-0009

48. Jaisser F, Farman N. Emerging roles of the mineralocorticoid receptor in pathology: toward new paradigms in clinical pharmacology. Pharmacol Rev. (2016) 68:49-75. doi: 10.1124/pr.115.011106

49. Lacolley P, Safar ME, Lucet B, Ledudal K, Labat C, Benetos A. Prevention of aortic and cardiac fibrosis by spironolactone in old normotensive rats. $\mathrm{J} \mathrm{Am}$ Coll Cardiol. (2001) 37:662-7. doi: 10.1016/S0735-1097(00)01129-3

50. Benetos A, Lacolley P, Safar ME. Prevention of aortic fibrosis by spironolactone in spontaneously hypertensive rats. Arterioscler Thromb Vasc Biol. (1997) 17:1152-6. doi: 10.1161/01.ATV.17.6.1152

51. DeMarco VG, Habibi J, Jia G, Aroor AR, Ramirez-Perez FI, MartinezLemus LA, et al. Low-dose mineralocorticoid receptor blockade prevents western diet-induced arterial stiffening in female mice. Hypertension. (2015) 66:99-107. doi: 10.1161/HYPERTENSIONAHA.115.05674

52. Virdis A, Neves MF, Amiri F, Viel E, Touyz RM, Schiffrin EL. Spironolactone improves angiotensin-induced vascular changes and oxidative stress. Hypertension. (2002) 40:504-10. doi: 10.1161/01.HYP.0000034738.79310.06

53. Savoia C, Touyz RM, Amiri F, Schiffrin EL. Selective mineralocorticoid receptor blocker eplerenone reduces resistance artery stiffness in hypertensive patients. Hypertension. (2008) 51:432-9. doi: 10.1161/HYPERTENSIONAHA.107.103267
54. Kithas PA, Supiano MA. Spironolactone and hydrochlorothiazide decrease vascular stiffness and blood pressure in geriatric hypertension. J Am Geriatr Soc. (2010) 58:1327-32. doi: 10.1111/j.1532-5415.2010.02905.x

55. O'Rourke MF, Nichols WW. Aortic diameter, aortic stiffness, and wave reflection increase with age and isolated systolic hypertension. Hypertension. (2005) 45:652-8. doi: 10.1161/01.HYP.0000153793.84859.b8

56. Kaess BM, Rong J, Larson MG, Hamburg NM, Vita JA, Levy D, et al. Aortic stiffness, blood pressure progression, and incident hypertension. JAMA. (2012) 308:875-81. doi: 10.1001/2012.jama.10503

57. Mitchell GF, Hwang SJ, Vasan RS, Larson MG, Pencina MJ, Hamburg NM, et al. Arterial stiffness and cardiovascular events: the Framingham Heart Study. Circulation. (2010) 121:505-11. doi: 10.1161/CIRCULATIONAHA.109.886655

58. Newfell BG, Iyer LK, Mohammad NN, McGraw AP, Ehsan A, Rosano $\mathrm{G}$, et al. Aldosterone regulates vascular gene transcription via oxidative stress-dependent and -independent pathways. Arterioscler Thromb Vasc Biol. (2011) 31:1871-80. doi: 10.1161/ATVBAHA.111.229070

59. Drüppel V, Kusche-Vihrog K, Grossmann C, Gekle M, Kasprzak B, Brand $\mathrm{E}$, et al. Long-term application of the aldosterone antagonist spironolactone prevents stiff endothelial cell syndrome. FASEB J. (2013) 27:3652-9. doi: 10.1096/fj.13-228312

60. Jia G, Habibi J, Aroor AR, Martinez-Lemus LA, DeMarco VG, RamirezPerez FI, et al. Endothelial mineralocorticoid receptor mediates diet-induced aortic stiffness in females. Circ Res. (2016) 118:935-43. doi: 10.1161/CIRCRESAHA.115.308269

61. Moss ME, DuPont JJ, Iyer SL, McGraw AP, Jaffe IZ. No significant role for smooth muscle cell mineralocorticoid receptors in atherosclerosis in the apolipoprotein-E knockout mouse model. Front Cardiovasc Med. (2018) 5:81. doi: $10.3389 /$ fcvm.2018.00081

62. Moss ME, Lu Q, Iyer SL, Engelbertsen D, Marzolla V, Caprio M, et al. Endothelial mineralocorticoid receptors contribute to vascular inflammation in atherosclerosis in a sex-specific manner. Arterioscler Thromb Vasc Biol. (2019) 39:1588-601. doi: 10.1161/ATVBAHA.119.312954

63. Usher MG, Duan SZ, Ivaschenko CY, Frieler RA, Berger S, Schütz G, et al. Myeloid mineralocorticoid receptor controls macrophage polarization and cardiovascular hypertrophy and remodeling in mice. J Clin Invest. (2010) 120:3350-64. doi: 10.1172/JCI41080

64. Sun XN, Li C, Liu Y, Du LJ, Zeng MR, Zheng XJ, et al. Tcell mineralocorticoid receptor controls blood pressure by regulating interferon-gamma. Circ Res. (2017) 120:1584-97. doi: 10.1161/CIRCRESAHA.116.310480

65. Shen ZX, Chen XQ, Sun XN, Sun JY, Zhang WC, Zheng XJ, et al. Mineralocorticoid receptor deficiency in macrophages inhibits atherosclerosis by affecting foam cell formation and efferocytosis. $J$ Biol Chem. (2017) 292:925-35. doi: 10.1074/jbc.M116.739243

66. Biernacka A, Frangogiannis NG. Aging and cardiac fibrosis. Aging Dis. (2011) 2:158-73.

67. Messaoudi S, Gravez B, Tarjus A, Pelloux V, Ouvrard-Pascaud A, Delcayre C, et al. Aldosterone-specific activation of cardiomyocyte mineralocorticoid receptor in vivo. Hypertension. (2013) 61:361-7. doi: 10.1161/HYPERTENSIONAHA.112.198986

68. Shen JZ, Morgan J, Tesch GH, Rickard AJ, Chrissobolis S, Drummond GR, et al. Cardiac tissue injury and remodeling is dependent upon MR regulation of activation pathways in cardiac tissue macrophages. Endocrinology. (2016) 157:3213-23. doi: 10.1210/en.2016-1040

69. Young MJ. Mechanisms of mineralocorticoid receptor-mediated cardiac fibrosis and vascular inflammation. Curr Opin Nephrol Hypertens. (2008) 17:174-80. doi: 10.1097/MNH.0b013e3282f56854

70. Leopold JA. Aldosterone, mineralocorticoid receptor activation, and cardiovascular remodeling. Circulation. (2011) 124:e466-8. doi: 10.1161/CIRCULATIONAHA.111.067918

71. Lombès M, Oblin ME, Gasc JM, Baulieu EE, Farman N, Bonvalet JP. Immunohistochemical and biochemical evidence for a cardiovascular mineralocorticoid receptor. Circ Res. (1992) 71:503-10. doi: 10.1161/01.RES.71.3.503

72. Bienvenu LA, Reichelt ME, Delbridge LM, Young MJ. Mineralocorticoid receptors and the heart, multiple cell types and multiple mechanisms: a focus on the cardiomyocyte. Clin Sci. (2013) 125:409-21. doi: 10.1042/CS20130050 
73. Favre J, Gao J, Zhang AD, Remy-Jouet I, Ouvrard-Pascaud A, Dautreaux $\mathrm{B}$, et al. Coronary endothelial dysfunction after cardiomyocyte-specific mineralocorticoid receptor overexpression. Am J Physiol Heart Circ Physiol. (2011) 300:H2035-43. doi: 10.1152/ajpheart.00552.2010

74. Wilson P, Morgan J, Funder JW, Fuller PJ, Young MJ. Mediators of mineralocorticoid receptor-induced profibrotic inflammatory responses in the heart. Clin Sci. (2009) 116:731-9. doi: 10.1042/CS20080247

75. Bienvenu LA, Morgan J, Rickard AJ, Tesch GH, Cranston GA, Fletcher EK, et al. Macrophage mineralocorticoid receptor signaling plays a key role in aldosterone-independent cardiac fibrosis. Endocrinology. (2012) 153:341625. doi: 10.1210/en.2011-2098

76. Herrada AA, Contreras FJ, Marini NP, Amador CA, González PA, Cortés CM, et al. Aldosterone promotes autoimmune damage by enhancing Th17-mediated immunity. J Immunol. (2010) 184:191-202. doi: 10.4049/jimmunol.0802886

77. Bettelli E, Carrier Y, Gao W, Korn T, Strom TB, Oukka M, et al. Reciprocal developmental pathways for the generation of pathogenic effector TH17 and regulatory T cells. Nature. (2006) 441:235-8. doi: 10.1038/nature04753

78. Li C, Sun XN, Zeng MR, Zheng XJ, Zhang YY, Wan Q, et al. Mineralocorticoid receptor deficiency in $\mathrm{T}$ cells attenuates pressure overload-induced cardiac hypertrophy and dysfunction through modulating T-cell activation. Hypertension. (2017) 70:137-47. doi: 10.1161/HYPERTENSIONAHA.117.09070

79. Susic D, Varagic J, Ahn J, Matavelli L, Frohlich ED. Long-term mineralocorticoid receptor blockade reduces fibrosis and improves cardiac performance and coronary hemodynamics in elderly SHR. Am J Physiol Heart Circ Physiol. (2007) 292:H175-9. doi: 10.1152/ajpheart.00660.2006

80. Gravez B, Tarjus A, Jaisser F. Mineralocorticoid receptor and cardiac arrhythmia. Clin Exp Pharmacol Physiol. (2013) 40:910-5. doi: 10.1111/1440-1681.12156

81. Gómez AM, Rueda A, Sainte-Marie Y, Pereira L, Zissimopoulos S, Zhu X, et al. Mineralocorticoid modulation of cardiac ryanodine receptor activity is associated with downregulation of FK506-binding proteins. Circulation. (2009) 119:2179-87. doi: 10.1161/CIRCULATIONAHA.108.805804

82. Ouvrard-Pascaud A, Sainte-Marie Y, Bénitah JP, Perrier R, Soukaseum C, Nguyen Dinh Cat A, et al. Conditional mineralocorticoid receptor expression in the heart leads to life-threatening arrhythmias. Circulation. (2005) 111:3025-33. doi: 10.1161/CIRCULATIONAHA.104.503706

83. Schnabel RB, Yin X, Gona P, Larson MG, Beiser AS, McManus DD, et al. 50 year trends in atrial fibrillation prevalence, incidence, risk factors, and mortality in the Framingham Heart Study: a cohort study. Lancet. (2015) 386:154-62. doi: 10.1016/S0140-6736(14)61774-8

84. Tsai CT, Chiang FT, Tseng CD, Hwang JJ, Kuo KT, Wu CK, et al. Increased expression of mineralocorticoid receptor in human atrial fibrillation and a cellular model of atrial fibrillation. J Am Coll Cardiol. (2010) 55:758-70. doi: 10.1016/j.jacc.2009.09.045

85. Davignon J, Ganz P. Role of endothelial dysfunction in atherosclerosis. Circulation. (2004) 109(Suppl 1):III27-32. doi: 10.1161/01.CIR.0000131515.03336.f8

86. Huang PL. Endothelial nitric oxide synthase and endothelial dysfunction. Curr Hypertens Rep. (2003) 5:473-80. doi: 10.1007/s11906-003-0055-4

87. Landmesser U, Drexler H. Endothelial function and hypertension. Curr Opin Cardiol. (2007) 22:316-20. doi: 10.1097/HCO.0b013e3281ca710d

88. Abiose AK, Mansoor GA, Barry M, Soucier R, Nair CK, Hager D. Effect of spironolactone on endothelial function in patients with congestive heart failure on conventional medical therapy. Am J Cardiol. (2004) 93:1564-6. doi: 10.1016/j.amjcard.2004.03.015

89. Farquharson CA, Struthers AD. Spironolactone increases nitric oxide bioactivity, improves endothelial vasodilator dysfunction, and suppresses vascular angiotensin I/angiotensin II conversion in patients with chronic heart failure. Circulation. (2000) 101:594-7. doi: 10.1161/01.CIR.101.6.594

90. Rajagopalan S, Duquaine D, King S, Pitt B, Patel P. Mineralocorticoid receptor antagonism in experimental atherosclerosis. Circulation. (2002) 105:2212-6. doi: 10.1161/01.CIR.0000015854.60710.10

91. Thai HM, Do BQ, Tran TD, Gaballa MA, Goldman S. Aldosterone antagonism improves endothelial-dependent vasorelaxation in heart failure via upregulation of endothelial nitric oxide synthase production. J Card Fail. (2006) 12:240-5. doi: 10.1016/j.cardfail.2006.01.002
92. Lother A, Fürst D, Bergemann S, Gilsbach R, Grahammer F, Huber $\mathrm{TB}$, et al. Deoxycorticosterone acetate/salt-induced cardiac but not renal injury is mediated by endothelial mineralocorticoid receptors independently from blood pressure. Hypertension. (2016) 67:130-8. doi: 10.1161/HYPERTENSIONAHA.115.06530

93. Marzolla V, Armani A, Mammi C, Moss ME, Pagliarini V, Pontecorvo L, et al. Essential role of ICAM-1 in aldosterone-induced atherosclerosis. Int J Cardiol. (2017) 232:233-42. doi: 10.1016/j.ijcard.2017.01.013

94. Park JB, Schiffrin EL. Cardiac and vascular fibrosis and hypertrophy in aldosterone-infused rats: role of endothelin-1. Am J Hypertens. (2002) 15(Pt 1):164-9. doi: 10.1016/S0895-7061(01)02291-9

95. Harvey AP, Montezano AC, Hood KY, Lopes RA, Rios F, Ceravolo G, et al. Vascular dysfunction and fibrosis in stroke-prone spontaneously hypertensive rats: the aldosterone-mineralocorticoid receptor-Nox1 axis. Life Sci. (2017) 179:110-9. doi: 10.1016/j.lfs.2017.05.002

96. Adler A, Messina E, Sherman B, Wang Z, Huang H, Linke A, et al. $\mathrm{NAD}(\mathrm{P}) \mathrm{H}$ oxidase-generated superoxide anion accounts for reduced control of myocardial $\mathrm{O} 2$ consumption by $\mathrm{NO}$ in old Fischer 344 rats. Am J Physiol Heart Circ Physiol. (2003) 285:H1015-22. doi: 10.1152/ajpheart.01 047.2002

97. Sindler AL, Fleenor BS, Calvert JW, Marshall KD, Zigler ML, Lefer DJ, et al. Nitrite supplementation reverses vascular endothelial dysfunction and large elastic artery stiffness with aging. Aging Cell. (2011) 10:429-37. doi: 10.1111/j.1474-9726.2011.00679.x

98. Sartório CL, Fraccarollo D, Galuppo P, Leutke M, Ertl G, Stefanon I, et al. Mineralocorticoid receptor blockade improves vasomotor dysfunction and vascular oxidative stress early after myocardial infarction. Hypertension. (2007) 50:919-25. doi: 10.1161/HYPERTENSIONAHA.107.093450

99. Briet M, Barhoumi T, Mian MOR, Coelho SC, Ouerd S, Rautureau Y, et al. Aldosterone-induced vascular remodeling and endothelial dysfunction require functional angiotensin type la receptors. Hypertension. (2016) 67:897-905. doi: 10.1161/HYPERTENSIONAHA.115.07074

100. McClain JL, Dorrance AM. Temporary mineralocorticoid receptor antagonism during the development of hypertension improves cerebral artery dilation. Exp Biol Med. (2014) 239:619-27. doi: $10.1177 / 1535370214522586$

101. Schäfer N, Lohmann C, Winnik S, van Tits LJ, Miranda MX, Vergopoulos A, et al. Endothelial mineralocorticoid receptor activation mediates endothelial dysfunction in diet-induced obesity. Eur Heart J. (2013) 34:3515-24. doi: 10.1093/eurheartj/eht095

102. Davel AP, Lu Q, Moss ME, Rao S, Anwar IJ, DuPont JJ, et al. Sexspecific mechanisms of resistance vessel endothelial dysfunction induced by cardiometabolic risk factors. J Am Heart Assoc. (2018) 7:e007675. doi: 10.1161/JAHA.117.007675

103. Mueller KB, Bender SB, Hong K, Yang Y, Aronovitz M, Jaisser $\mathrm{F}$, et al. Endothelial mineralocorticoid receptors differentially contribute to coronary and mesenteric vascular function without modulating blood pressure. Hypertension. (2015) 66:988-97. doi: 10.1161/HYPERTENSIONAHA.115.06172

104. Mahmud A, Feely J. Aldosterone-to-renin ratio, arterial stiffness, and the response to aldosterone antagonism in essential hypertension. Am J Hypertens. (2005) 18:50-5. doi: 10.1016/j.amjhyper.2004.08.026

105. White WB, Duprez D, St. Hillaire R, Krause S, Roniker B, Kuse-Hamilton $\mathrm{J}$, et al. Effects of the selective aldosterone blocker eplerenone versus the calcium antagonist amlodipine in systolic hypertension. Hypertension. (2003) 41:1021-6. doi: 10.1161/01.HYP.0000067463.13172.EA

106. Hwang MH, Yoo JK, Luttrell M, Kim HK, Meade TH, English M, et al. Role of mineralocorticoid receptors in arterial stiffness in human aging. Exp Gerontol. (2013) 48:701-4. doi: 10.1016/j.exger.2013.05.058

107. Hwang MH, Yoo JK, Luttrell M, Kim HK, Meade TH, English $\mathrm{M}$, et al. Acute effect of mineralocorticoid receptor antagonism on vascular function in healthy older adults. Exp Gerontol. (2016) 73:86-94. doi: 10.1016/j.exger.2015.11.017

108. Heylen E, Huang A, Sun D, Kaley G. Nitric oxide-mediated dilation of arterioles to intraluminal administration of aldosterone. J Cardiovasc Pharmacol. (2009) 54:535-42. doi: 10.1097/FJC.0b013e3181bfb00d

109. Lakatta EG, Levy D. Arterial and cardiac aging: major shareholders in cardiovascular disease enterprises: part II: the aging heart in 
health: links to heart disease. Circulation. (2003) 107:346-54. doi: 10.1161/01.CIR.0000048893.62841.F7

110. Judge S, Jang YM, Smith A, Hagen T, Leeuwenburgh C. Age-associated increases in oxidative stress and antioxidant enzyme activities in cardiac interfibrillar mitochondria: implications for the mitochondrial theory of aging. FASEB J. (2005) 19:419-21. doi: 10.1096/fj.04-2622fje

111. Ungvari Z, Orosz Z, Labinskyy N, Rivera A, Xiangmin Z, Smith K, et al. Increased mitochondrial $\mathrm{H} 2 \mathrm{O} 2$ production promotes endothelial NFkappaB activation in aged rat arteries. Am J Physiol Heart Circ Physiol. (2007) 293:H37-47. doi: 10.1152/ajpheart.01346.2006

112. Pogribny IP, Beland FA. DNA hypomethylation in the origin and pathogenesis of human diseases. Cell Mol Life Sci. (2009) 66:2249-61. doi: 10.1007/s00018-009-0015-5

113. Laukkanen MO, Mannermaa S, Hiltunen MO, Aittomäki S, Airenne $\mathrm{K}$, Jänne $\mathrm{J}$, et al. Local hypomethylation in atherosclerosis found in rabbit ec-sod gene. Arterioscler Thromb Vasc Biol. (1999) 19:2171-8. doi: 10.1161/01.ATV.19.9.2171

114. Scull CM, Tabas I. Mechanisms of ER stress-induced apoptosis in atherosclerosis. Arterioscler Thromb Vasc Biol. (2011) 31:2792-7. doi: 10.1161/ATVBAHA.111.224881

115. Sica DA. Mineralocorticoid receptor antagonists for treatment of hypertension and heart failure. Methodist Debakey Cardiovasc J. (2015) 11:235-9. doi: 10.14797/mdcj-11-4-235

116. Kearney PM, Whelton M, Reynolds K, Muntner P, Whelton PK, He J. Global burden of hypertension: analysis of worldwide data. Lancet. (2005) 365:217-23. doi: 10.1016/S0140-6736(05)17741-1

117. Go AS, Mozaffarian D, Roger VL, Benjamin EJ, Berry JD, Borden WB, et al. Heart disease and stroke statistics-2013 update: a report from the American Heart Association. Circulation. (2013) 127:e6-245. doi: 10.1161/CIR.0b013e31828124ad

118. Pitt B, Zannad F, Remme WJ, Cody R, Castaigne A, Perez A, et al. The effect of spironolactone on morbidity and mortality in patients with severe heart failure. Randomized Aldactone Evaluation Study Investigators. $N$ Engl J Med. (1999) 341:709-17. doi: 10.1056/NEJM1999090234 11001

119. Pitt B, Williams G, Remme W, Martinez F, Lopez-Sendon J, Zannad F, et al. The EPHESUS trial: eplerenone in patients with heart failure due to systolic dysfunction complicating acute myocardial infarction. Eplerenone Post-AMI Heart Failure Efficacy and Survival Study. Cardiovasc Drugs Ther. (2001) 15:79-87.

120. Pitt B, Remme W, Zannad F, Neaton J, Martinez F, Roniker B, et al. Eplerenone, a selective aldosterone blocker, in patients with left ventricular dysfunction after myocardial infarction. N Engl J Med. (2003) 348:1309-21. doi: 10.1056/NEJMoa030207

121. Pitt B, Pfeffer MA, Assmann SF, Boineau R, Anand IS, Claggett B, et al. Spironolactone for heart failure with preserved ejection fraction. $\mathrm{N} \mathrm{Engl} \mathrm{J}$ Med. (2014) 370:1383-92. doi: 10.1056/NEJMoa1313731

122. Pfeffer MA, Claggett B, Assmann SF, Boineau R, Anand IS, Clausell N, et al. Regional variation in patients and outcomes in the treatment of preserved cardiac function heart failure with an aldosterone antagonist. (TOPCAT) trial. Circulation. (2015) 131:34-42. doi: 10.1161/CIRCULATIONAHA.114.013255

123. Japp D, Shah A, Fisken S, Denvir M, Shenkin S, Japp A. Mineralocorticoid receptor antagonists in elderly patients with heart failure: a systematic review and meta-analysis. Age Ageing. (2017) 46:18-25. doi: 10.1093/ageing/ afw138

124. Merrill M, Sweitzer NK, Lindenfeld J, Kao DP. Sex differences in outcomes and responses to spironolactone in heart failure with preserved ejection fraction: a secondary analysis of TOPCAT trial. JACC Heart Fail. (2019) 7:228-38. doi: 10.1016/j.jchf.2019.01.003

125. Dabrowski R, Borowiec A, Smolis-Bak E, Kowalik I, Sosnowski C, Kraska A, et al. Effect of combined spironolactone- $\beta$-blocker \pm enalapril treatment on occurrence of symptomatic atrial fibrillation episodes in patients with a history of paroxysmal atrial fibrillation. (SPIR-AF study). Am J Cardiol. (2010) 106:1609-14. doi: 10.1016/j.amjcard.2010.07.037

126. Fudim M, Liu PR, Shrader P, Blanco RG, Allen LA, Fonarow GC, et al. Mineralocorticoid receptor antagonism in patients with atrial fibrillation: findings from the ORBIT-AF. (outcomes registry for better informed treatment of atrial fibrillation) Registry. J Am Heart Assoc. (2018) 7:e007987. doi: 10.1161/JAHA.117.007987

127. Williams B, Mancia G, Spiering W, Agabiti Rosei E, Azizi M, Burnier M, et al. 2018 ESC/ESH Guidelines for the management of arterial hypertension. Eur Heart J. (2018) 39:3021-104. doi: 10.1093/eurheartj/ehy339

128. Corrao G, Mazzola P, Monzio Compagnoni M, Rea F, Merlino L, Annoni G, et al. Antihypertensive medications, loop diuretics, and risk of hip fracture in the elderly: a population-based cohort study of 81,617 italian patients newly treated between 2005 and 2009. Drugs Aging. (2015) 32:927-36. doi: 10.1007/s40266-015-0306-5

129. Juurlink DN, Mamdani MM, Lee DS, Kopp A, Austin PC, Laupacis A, et al. Rates of hyperkalemia after publication of the Randomized Aldactone Evaluation Study. N Engl J Med. (2004) 351:543-51. doi: 10.1056/NEJMoa040135

130. Pitt B. The role of mineralocorticoid receptor antagonists (MRAs) in very old patients with heart failure. Heart Fail Rev. (2012) 17:573-9. doi: 10.1007/s10741-011-9286-7

131. Haller H, Bertram A, Stahl K, Menne J. Finerenone: a new mineralocorticoid receptor antagonist without hyperkalemia: an opportunity in patients with CKD? Curr Hypertens Rep. (2016) 18:41. doi: 10.1007/s11906-016-0649-2

132. Liu LC, Schutte E, Gansevoort RT, van der Meer P, Voors AA. Finerenone : third-generation mineralocorticoid receptor antagonist for the treatment of heart failure and diabetic kidney disease. Expert Opin Investig Drugs. (2015) 24:1123-35. doi: 10.1517/13543784.2015.1059819

133. Kolkhof P, Jaisser F, Kim SY, Filippatos G, Nowack C, Pitt B. Steroidal and novel non-steroidal mineralocorticoid receptor antagonists in heart failure and cardiorenal diseases: comparison at bench and bedside. Handb Exp Pharmacol. (2017) 243:271-305. doi: 10.1007/164_2016_76

134. Bakris GL, Agarwal R, Chan JC, Cooper ME, Gansevoort RT, Haller $\mathrm{H}$, et al. Effect of Finerenone on Albuminuria in patients with diabetic nephropathy: a randomized clinical trial. JAMA. (2015) 314:884-94. doi: 10.1001/jama.2015.10081

135. Filippatos G, Anker SD, Böhm M, Gheorghiade M, Køber L, Krum H, et al. A randomized controlled study of Finerenone vs. Eplerenone in patients with worsening chronic heart failure and diabetes mellitus and/or chronic kidney disease. Eur Heart J. (2016) 37:2105-14. doi: 10.1093/eurheartj/ehw132

136. Grune J, Beyhoff N, Smeir E, Chudek R, Blumrich A, Ban Z, et al. Selective mineralocorticoid receptor cofactor modulation as molecular basis for Finerenone's antifibrotic activity. Hypertension. (2018) 71:599-608. doi: 10.1161/HYPERTENSIONAHA.117.10360

137. Gorini S, Marzolla V, Mammi C, Armani A, Caprio M. Mineralocorticoid receptor and aldosterone-related biomarkers of end-organ damage in cardiometabolic disease. Biomolecules. (2018) 8:E96. doi: $10.3390 /$ biom 8030096

Conflict of Interest Statement: MC received research grants from Bayer AG.

The remaining authors declare that the research was conducted in the absence of any commercial or financial relationships that could be construed as a potential conflict of interest.

Copyright (๔ 2019 Gorini, Kim, Infante, Mammi, La Vignera, Fabbri, Jaffe and Caprio. This is an open-access article distributed under the terms of the Creative Commons Attribution License (CC BY). The use, distribution or reproduction in other forums is permitted, provided the original author(s) and the copyright owner(s) are credited and that the original publication in this journal is cited, in accordance with accepted academic practice. No use, distribution or reproduction is permitted which does not comply with these terms. 